Ecos del Simbolismo en la métrica modernista... Rhythmica, VIII, 2010

\title{
ECOS DEL SIMBOLISMO EN LA MÉTRICA MODERNISTA: EL VERSO ALEJANDRINO
}

\section{María Victoria Utrera TORREMOCHA}

Resumen: En este trabajo se estudia, especialmente en la obra de Rubén Darío, el tipo de verso alejandrino con el acento final del primer hemistiquio sobre sílabas generalmente átonas o con encabalgamiento léxico (tmesis) entre hemistiquios. La huella del simbolismo es clara no sólo en esta clase de verso, sino en otros aspectos métricos del modernismo. De acuerdo con los principios poéticos de Paul Verlaine, este tipo de alejandrino no supone una verdadera ruptura con el modelo anterior, ni ha de clasificarse como verso de trece sílabas.

Palabras clave: verso alejandrino, simbolismo, modernismo, Rubén Darío, Paul Verlaine.

Abstract: This study, and particularly with regard to Rubén Darío's works, analyses the type of alexandrine verse-line in which the final stress of the first hemistich falls upon syllables which are generally unaccented or which occur where lexical syllable cross-over (tmesis) is found to be trans-hemistichal. Clearly there is a presence of Symbolism not only in this kind of line, but also in other metrical features of Hispanic Modernism. In keeping with Paul Verlaine's poetic principles, this kind of 
alexandrine does not constitute a true break with previous patterning, nor can it be classified as a thirteensyllable line.

Key-words: alexandrine line, Symbolism, Hispanic Modernism, Rubén Darío, Paul Verlaine. 


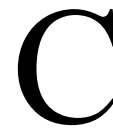

UANDO Paul Verlaine en su "Art poétique" (1874) defiende la nuance como premisa del arte está estableciendo que la suavidad, la musicalidad y la delicadeza, y no, desde luego, el sonsonete marcado del compás rutinario, son los caminos de la nueva poesía. En esto coincide plenamente con las formas imprecisas, que no amorfas, del impresionismo de la época, es decir, del simbolismo poético. La levedad y la evanescencia, el matiz y el equívoco, la languidez y la vaguedad son los nuevos valores, de ahí la musicalidad, que se traduce en el verso impar, explícitamente mencionado, y en otros aspectos formales de carácter métrico y retórico ${ }^{1}$. Frente a este tipo de poesía leve y sutil, se alza la

1 “De la musique avant toute chose, / Et pour cela préfère l'Impair / Plus vague et plus soluble dans l'air, / Sans rien en lui qui pèse ou qui pose. // Il faut aussi que tu n'ailles point / Choisir tes mots sans quelque méprise: / Rien de plus cher que la chanson grise / Où l'Indécis au Précis se joint. // C'est des beaux yeux derrières des voiles, / C'est le grand jour tremblant de midi, / C'est, par un ciel d'automne attiédi, / Le bleu fouillis des claires étoiles! // Car nous voulons la Nuance encor, / Pas la couleur, rien que la nuance! / Oh! la nuance seule fiance / Le rêve au rêve et la flûte au cor! // Fuis du plus loin la Pointe assassine, / L'Esprit cruel et le rire impur, / Qui font pleurer le yeux de l'Azur, / Et tout ce ail de basse cuisine! // Prends l'éloquence et tords-lui son cou! / Tu feras bien, en train d'énergie, / De rendre un peu la Rime assagie. / Si l'on n'y veille, elle ira jusqu'où? // O qui dira les torts de la Rime! / Quel enfant sourd ou quel nègre fou / Nous a forgé ce bijou d'un sou / Qui sonne creux et faux sous la lime? // De la musique encore et toujours! / Que ton vers soit la chose envolée / Qu'on sent qui fuit d'une âme en allée / Vers d'autres cieux à d'autres amours. // Que ton vers soit la bonne aventure / Éparse au vent crispé du matin / Qui va fleurant la menthe et le thym... / Et tout le reste est littérature." VERLAINE, Paul: Oeuvres poétiques. Edición de Jacques Robichez. París: Garnier, 1995, pp. 261262. ("Prefiere la música a toda otra cosa, / persigue la sílaba impar, imprecisa, / más ágil y más soluble en la brisa, / que-libre de lastre- ni pesa ni posa. // Que vuestra palabra tenga un indeciso / y equívoco paso, si lo decidís. / Nada más hermoso que la canción gris, / donde lo indeciso se une a lo preciso. // Detrás de los velos, las miradas bellas. / En el mediodía, una luz que oscila. / Un cielo de otoño templado perfila / un confuso azul de claras estrellas. // Matiz, claroscuro, 
poesía rotunda, elocuente, de la rima sonora, falsa y hueca, es decir, la literatura, opuesta a la verdadera y nueva poesía, inaugurada por Verlaine y los poetas modernos. Sin embargo, como explica Pierre Brunel ${ }^{2}$, la imprecisión no supone desorden: lo impreciso va, en la poética verlainiana, de la mano de lo preciso, algo patente no sólo en el "Art poétique" de 1874, sino en el menos conocido "L'Art poétique ad hoc", de Invectives (1895).

La sutileza y la suavidad son cualidades importantes frente a la rotunda solidez del verso de épocas anteriores. La forma rítmica continua y reiterada es característica, como hicieron ver en repetidas ocasiones los poetas simbolistas contemporáneos y posteriores a Verlaine, del alejandrino clásico francés, verso emblemático de la tradición poética francesa que se compone de doce sílabas y está dividido en dos hemistiquios de seis sílabas cada uno, con acentos en las sílabas sexta y duodécima. Ya Victor Hugo comenzó a suavizar rítmicamente el alejandrino, pero fue Verlaine quien llevó a mejor término la modulación decadente del mismo en la manera que algunos llaman alejandrino tripartito. Se trataba precisamente de atenuar - pero no de eliminar- la marcada pausa central de este verso compuesto, de tal modo que el efecto acústico y rítmico fuera de mayor imprecisión. El verso, así, se lleva a una tensión que habría supuesto, según algunos conservadores de la

veladura sola. / Nada de color. Sólo los matices. / El matiz compone parejas felices / entre sueño y sueño, entre flauta y viola. // Aleja de ti la punta asesina, / la gracia cruel y el rictus de hielo, / que harían llorar los ojos del cielo / con todo ese ajo de mala cocina. // Coge la retórica y amordázala. / Sujeta la rima, y dale sentido / a esa carambola de vano sonido, / que, si la dejamos, ¿hasta dónde irá? // ¡Ah, la sinrazón de la pobre rima! / ¿Qué párvulo sordo, qué negro mochales, / nos forjó esa joya de cuatro reales / que suena a oropel hueco con la lima? // La música siempre, y en tono menor. / Que tu verso sea fugaz y suave, / sutil y ligero, como vuelo de ave / que busca otros cielos y otro nuevo amor. // Que tu verso sea la buena ventura / esparcida al aire de la madrugada, / que huele a tomillo y a menta granada... / Todo lo demás es literatura." Traducción de TORRE, Esteban: 33 poemas simbolistas, Baudelaire, Verlaine, Rimbaud, Mallarmé. Edición bilingüe. Madrid: Visor, 1995, pp. 71-73).

2 Véase BRUNEL, Pierre: "Sur trois titres verlainiens: Poèmes saturniens, Fêtes galantes, Romances sans paroles", en Steve Murphy (dir.), Lectures de Verlaine. 'Poèmes saturniens', 'Fêtes galantes', 'Romances sans paroles'. Rennes: Presses Universitaires de Rennes, 2007, pp. 19-20. 
época, una verdadera traición a las buenas maneras literarias, propia de decadentes y de poetas nerviosos y enfermos. Se correspondía con la literatura de la enfermedad, la que anunciaran los románticos muchos años antes. La nevrose ya no sería sólo un tema literario, sino que tendría ahora una manifestación métrica, además de acompañarse de otros procedimientos estilísticos calificados como decadentes, como, por ejemplo, los juegos sinestésicos, tan denostados por Paul Bourget. El tema y los motivos de la enfermedad tienen, pues, en poesía sus propias vías de expresión. De la misma manera, la emblemática novela de Huysmans, A rebours (1884), fue breviario del decadentismo y de la nevrose no sólo por su contenido, sino por su estructura y configuración narrativas.

Algunos estudios siguen viendo en los experimentos con el alejandrino una ruptura abierta del verso y llegan a afirmar que Verlaine "deshizo la estructura clásica de los metros franceses"'. El uso frecuente y atrevido que, sin duda, el poeta de Sagesse, como otros simbolistas, hace del encabalgamiento (enjambement) no impide, no obstante, como se sabe, la pausa versal o pausa entre hemistiquios, esto es, la cesura, por más que el encabalgamiento entre ambos hemistiquios sea de carácter abrupto y llegue incluso a romper una palabra. En el poema "Lassitude" vemos un claro ejemplo de este tipo de alejandrino en el primer verso del primer cuarteto:

De la douceur, de la douceur, de la douceur!

Calme un peu ces transports fébriles, ma charmante.

Même au fort du déduit parfois, vois-tu, l'amante

Doit avoir l'abandon paisible de la soeur ${ }^{4}$.

La modulación rítmica del verso inicial, frente a los posteriores, es mucho más atenuada. Es ésta una de las aportaciones más interesantes de Verlaine, aunque hay que advertir que no es fácil la recreación de esta clase de alejandrino. No todos los poetas dominan este ritmo. En este sentido, tampoco los traductores aciertan siempre. Algunos prefieren simplemente

3 FERRERES, Rafael: Verlaine y los modernistas españoles. Madrid: Gredos, 1975, p. 143.

4 VERLAINE, Paul: Oeuvres poétiques, cit., p. 28. 
ofrecer al lector el habitual alejandrino, ante la clara dificultad de traducir también la forma del verso, es decir, la forma de la expresión. Una buena traducción de los poemas de Verlaine es la que publicó Carlos Pujol en la editorial Trieste de Madrid, en 1986, quien, al traducir el primer cuarteto de "Lassitude", obvia, sin embargo, el ritmo del primer verso:

Suavidad, suavidad, suavidad, oh mi amada, pon un poco de calma en tus gestos febriles.

Que a la amante en la entrega le conviene tener ese dulce abandono que es sosiego de hermana.

De un excelente sentido poético, es la versión de Esteban Torre recogida en sus 33 poemas simbolistas, en que se traduce el primer verso con la forma del alejandrino francés, además de mantener la rima a lo largo de todo el soneto:

Serenidad, serenidad, serenidad.

Calma un poco ese impulso febril que te impacienta.

Mira que hasta en el bronco rugir de la tormenta

Hay una franja tenue de blanca claridad.

Esta clase de alejandrino, que interesó a Arthur Rimbaud y fue acogida con simpatía por los simbolistas posteriores, caló también en otras literaturas. Es el caso del modernismo hispánico, en que hay numerosos ejemplos. En la literatura hispánica, los modernistas supieron asimilar, al igual que sucedió con otros elementos estilísticos, este tipo de verso. Los grandes maestros son Rubén Darío y Juan Ramón Jiménez, pero no son los únicos. Es notable que el alejandrino en su forma habitual se haya extendido a lo largo de los siglos xx y XXI hasta llegar a ser un verso tan frecuente como los versos endecasílabo y octosílabo, bien en poemas de ritmo endecasilábico, bien en poemas escritos sólo en alejandrinos. Se ha de reconocer ahí la deuda con la poesía de Francia a través del camino modernista y simbolista.

Las discusiones sobre este tipo de alejandrino se dieron ya en su época, tanto en los tratados de métrica francesa y en los comentarios críticos de poesía, como en los correspondientes en 
español, y continúan hasta hoy. Los tratadistas debaten todavía en torno a si esta clase de alejandrino, cuya cesura plantea problemas de lectura por la disonancia entre métrica y sintaxis, ha de leerse como tripartito o bipartito; en el alejandrino español la discusión se plantea, además, en términos de si tiene trece o catorce sílabas. Un buen planteamiento histórico y teórico de las principales actitudes respecto a este problema es expuesto en el artículo de José Domínguez Caparrós "Métrica y poética de Rubén Darío"s. A la luz de la métrica comparada, Esteban Torre ha estudiado concienzudamente el alejandrino en diversos trabajos, refiriéndose tanto al alejandrino español como al francés y no ha dejado dudas sobre su naturaleza bipartita, haciendo ver que los experimentalismos con el alejandrino no afectan a su estructura esencial de dos hemistiquios simétricos o isostiquios. El alejandrino español mal llamado de trece sílabas, falsamente irregular, sería sólo el resultado de una escansión errónea, que no tiene en cuenta fenómenos como el de la cesura $^{6}$. De acuerdo con las opiniones de Benoît de Cornulier, el profesor Torre descarta acertadamente cualquier irregularidad silábica en los alejandrinos de Verlaine y sus seguidores: "es siempre Verlaine quien suele citarse cuando se quiere dar un ejemplo de alejandrino "anárquico", "desarticulado", "libre" de toda regla [...]. Pues bien, si no se ignora el fenómeno métrico de la cesura, la medida de estos versos se ajusta fácilmente" al esquema habitual de dos hemistiquios simétricos ${ }^{7}$. Los versos alejandrinos españoles seguirían la misma escansión, aunque con la convención métrica de sumar o restar una sílaba según sea el final de verso o hemistiquio agudo o esdrújulo. En todos los casos, sea en francés o en español, el acento final de

5 Véase DOMÍNGUEZ CAPARRÓS, José: "Métrica y poética en Rubén Darío", en Tomás Albaladejo, Javier Blasco y Ricardo de la Fuente (eds.), El modernismo. Renovación de los lenguajes poéticos I. Valladolid: Universidad de Valladolid, 1990, pp. 36-44.

6 Véase TORRE, Esteban: El ritmo del verso (Estudios sobre el cómputo silábico y la distribución acentual, a la luz de la Métrica Comparada, en el verso español moderno). Murcia: Servicio de Publicaciones de la Universidad de Murcia, 1999, pp. 79-99.

7 Véase TORRE, Esteban: Métrica española comparada. Sevilla: Servicio de Publicaciones de la Universidad de Sevilla, 2000, pp. 89-90, y TORRE, Esteban: El ritmo del verso, cit., pp. 55-70. 
hemistiquio va siempre en la sexta sílaba de cada uno de ellos.

Del mal llamado alejandrino de trece sílabas hay numerosos ejemplos en las obras modernistas, sin duda por influencia de la métrica francesa simbolista. Es el caso del verso de Rubén Darío “¡Oh, Sor María! ¡Oh, Sor María! ¡Oh, Sor María!", perteneciente al poema segundo de "Retratos" incluido en Cantos de vida y esperanza. Como ya indicara Dámaso Alonso $^{8}$, es un verso alejandrino de catorce sílabas, a cuyo primer hemistiquio, terminado y acentuado en sexta sílaba (“¡oh-sór-ma-rí-aoh-sór”), habría que sumar una sílaba más. Pero otros muchos son los alejandrinos de influencia francesa utilizados por Darío. Además de los de terminación aguda, o con monosílabo al final de hemistiquio, existen otros con encabalgamiento léxico o tmesis. Encontramos algunos ejemplos en Prosas profanas (1896), pero su empleo se incrementa muy considerablemente en Cantos de vida y esperanza (1905), cuando ya el poeta nicaragüense se asienta plenamente en la estética modernista y simbolista. De Prosas profanas es "Marina", donde usa Darío el alejandrino con tmesis en el verso 7 -"adiós, peñascos enemigos del poeta" ("a-dióspe-ñás-cos-é $(6+1=7)$ // ne-mí-gos-del-po-é-ta (7)")-; en el verso 15 - "y provenía de"- deja la preposición al final del verso, haciendo aguda su terminación ("y-pro-ve-ní-a-dé $(6+1=7)$ "), esquema que repite en el primer hemistiquio del verso 26: "Entonces, fijo del azur en lo infinito" ("en-tón-cesfí-jo-dél (6+1=7) // a-zúr-en-loin-fi-ní-to (7)”).

El soneto "Pegaso", en alejandrinos, recurre a la acentuación aguda en el monosílabo final de hemistiquio del verso 11: "coronada con el laurel del Rey del día", jugando también con la rima en eco entre "el" y "laurel". La escansión del verso sería: "co-ro-ná-da-con-él $(6+1=7)$ // lau-rél-del-réydel-dí-a (7)".

En los versos segundo, noveno y décimo del siguiente fragmento de "Nocturno" de Cantos de vida y esperanza se hallan también algunos casos de esta clase de alejandrinos:

8 ALONSO, Dámaso: Poetas españoles contemporáneos. Tercera edición aumentada. Madrid: Gredos, 1965, pp. 59-60. 
Esperanza olorosa a hierbas frescas, trino del ruiseñor primaveral y matinal, azucena tronchada por un fatal destino, rebusca de la dicha, persecución del mal... $\mathrm{El}$ ánfora funesta del divino veneno que ha de hacer por la vida la tortura interior, la conciencia espantable de nuestro humano cieno y el horror de sentirse pasajero, el horror de ir a tientas, en intermitentes espantos, hacia lo inevitable, desconocido, y la pesadilla brutal de este dormir de llantos ¡de la cual no hay más que Ella que nos despertará!

La escansión del verso segundo y noveno ha de hacerse de la siguiente manera: "del-rui-se-ñór-pri-má $(6+1=7)$ // ve-rál-y-ma-ti-nál $(6+1=7)$ ", "deir-a-tién-tas-en-ín $(6+1=7)$ // ter-mi-tén-tes-es-pán-tos (7)"; la del verso décimo sería como sigue: "ha-cia-loi-ne-vi-tá-ble (7) // des-co-no-cí-doylá (6+1=7)". La influencia francesa simbolista es obvia igualmente en la alternancia de rimas femeninas y masculinas.

Alejandrinos con tmesis hay también en "Canto de esperanza", de Cantos de vida y esperanza: "Ha nacido el apocalíptico Anticristo" y "que el soñador, imperial meditabundo", en los que la cesura rompe la palabra. El primer hemistiquio llega hasta la sexta sílaba del verso: "há-na-cí-doel-a-pó $(6+1=7)$ // ca-líp-ti-coan-ti-crís-to (7)"; "queel-so-ña-dór,-impé $(6+1=7)$ // ri-ál-me-di-ta-bún-do (7)". En el soneto alejandrino "A Phocás el campesino", del mismo libro, reaparece la tmesis entre los hemistiquios del primer verso del primer terceto: "Sueña, hijo mío, todavía, y cuando crezcas". La cesura rompe el adverbio "todavía": "sué-ñahi-jo-mí-o-tó $(6+1=7)$ // da-ví-ay-cuan-do-créz-cas (7)". Un nuevo encabalgamiento léxico se encuentra en el segundo verso de los serventesios de "Ay, triste del que un día...", de Cantos de vida y esperanza, en el segundo verso: "pone los ojos e interroga. Está perdido." La cesura rompe el verbo en la sexta sílaba: "pó-ne-losó-jos-éin $(6+1=7) / /$ te-rró-gaes-tá-per-dí-do (7)".

Entre los muchos sonetos alejandrinos de Darío, algunos otros contienen muestras de este alejandrino francés. Es el caso del conocido "Yo persigo una forma", en que el primer 
verso del primer terceto ha de leerse con una dislocación acentual: "Y no hallo sino la palabra que huye." Le medida del verso sería: "Y-no-há-llo-si-nó $(6+1=7)$ // la-pa-lá-braque-hú-ye (7)”.

En Cantos de vida y esperanza, el poema XXXII "Nocturno" presenta también algunos alejandrinos con final de hemistiquio en monosílabo agudo o con tmesis:

Los que auscultasteis el corazón de la noche, los que por el insomnio tenaz habéis oído el cerrar de una puerta, el resonar de un coche lejano, un eco vago, un ligero ruido...

En los instantes del silencio misterioso, cuando surgen de su prisión los olvidados, en la hora de los muertos, en la hora del reposo, ¡sabréis leer estos versos de amargor impregnados!... Como en un vaso vierto en ellos mis dolores de lejanos recuerdos y desgracias funestas, y las tristes nostalgias de mi alma, ebria de flores, y el duelo de mi corazón, triste de fiestas.

Y el pesar de no ser lo que yo hubiera sido

Los versos 1, 5, 6, 12 y 13 han de escandirse de la siguiente manera: "los-queaus-cul-tás-teis-él $(6+1=7)$ // co-ra-zón-dela-nó-che" (7), "en-los-ins-tán-tes-dél $(6+1=7)$ // si-lén-ciomis-te-rió-so (7)", "cuan-do-súr-gen-de-sú $(6+1=7)$ // prisión-los-ol-vi-dá-dos (7)", "yel- dué-lo-de-mi-có $(6+1=7) / /$ ra-zón-tris-te-de-fiés-tas (7)", "yel-pe-sár-de-no-sér $(6+1=7)$ // lo-que-yóhu-bie-ra-sí-do (7)".

Con monosílabo agudo hay otros casos en Cantos de vida y esperanza. En "De otoño", por ejemplo, aparte de otros hemistiquios agudos, el penúltimo verso de los dos serventesios alejandrinos tiene al final una preposición con incremento acentual:

Yo, pobre árbol, produje, al amor de la brisa, cuando empecé a crecer, un vago y dulce són.

Pasó ya el tiempo de la juvenil sonrisa:

¡Dejad al huracán mover mi corazón! 
La medida del tercer verso sería: "Pa-só-yael-tiém-po-dé $(6+1=7)$ // la-ju-ve-níl-son-rí-sa (7)".

En el poema "Lo fatal", de Cantos de vida y esperanza, Darío hace gala de este tipo de acentuaciones en monosílabos a final de verso y hemistiquios:
Dichoso el árbol que es apenas sensitivo, y más la piedra dura porque ésa ya no siente, pues no hay dolor más grande que el dolor de ser vivo, ni mayor pesadumbre que la vida consciente. Ser, y no saber nada, y ser sin rumbo cierto, y el temor de haber sido y un futuro terror... Y el espanto seguro de estar mañana muerto, y sufrir por la vida y por la sombra y por lo que no conocemos y apenas sospechamos, y la carne que tienta con sus frescos racimos, y la tumba que aguarda con sus fúnebres ramos, iy no saber adónde vamos, ni de dónde venimos!...

El esquema métrico de sílabas con terminación aguda $(6+1=7)$ afectaría a los siguientes hemistiquios: "Dichoso el árbol que es" ("Di-chó-soel-ár-bol-queés"), "y un futuro terror..." ("yun-fu-tú-ro-te-rrór"), "y por la sombra y por" ("ypor-la-sóm-bray-pór"). La influencia simbolista se aprecia, además, en el juego de sonoridades y, como suele ocurrir en este tipo de versos, en los desplazamientos acentuales, por los que la preposición o el artículo reciben el acento de final de verso o de hemistiquio. Del mismo modo, es evidente la huella simbolista en los encabalgamientos, de gran interés por su intensidad y significación en la creación de expectativas del poema, como el que se produce entre los versos 8 y 9: la preposición queda al final sugiriendo el abismo de incertidumbre.

De Manuel Machado es el alejandrino "La Caridad, la Caridad, la Caridad" ("Kyrie eleison", Los cantares). Recurre aquí, como Verlaine en "Lassitud", a la geminación como recurso retórico, figura muy usada por el simbolismo en general, como otras de repetición. Juan Ramón Jiménez se sirve también a menudo de este tipo de alejandrino en sus dos modalidades, con encabalgamiento léxico y con monosílabo 
final agudo. En Estio (1916) lo combina con el ritmo endecasilábico en su último poema, “¡Silencio!”, con una técnica que empleará en el Diario de un poeta reciéncasado (1917) y que no abandonará a lo largo de toda su obra:

No, no digáis lo que no he dicho.

Tu luna llena me lo tape, cielo inmenso, en la noche solemne;

tú, río que lo sabes, sigue hablando como quien no lo sabe, paralelo en tu huir infinito a mi secreto pensamiento yerto; aunque lo cantes, pájaro, yo solo sepa desde dentro que lo cantas cual yo en abril te lo cantaba; tú, rosa última, guárdalo en tus pétalos como en mi corazón; llévalo tú y déjatelo, viento...

¡No, no, no lo digáis!

Siga todo secreto eternamente, mientras jira el mundo soñando, nunca dicho ya por nadie, con mi silencio eterno.

En este conjunto de versos endecasilábicos, los dos alejandrinos se miden del siguiente modo: "tu-lú-na-llé-na-mé $(6+1=7)$ // lo-tá-pe-cié-loin-mén-so (7)", "que-lo-cán-tascual-yoén $(6+1=7)$ // a-bríl-te-lo-can-tá-ba (7)".

La combinación entre versos de ritmo endecasilábico con dislocación acentual y este tipo de alejandrino aparece en el poema 115 de Piedra y Cielo (1919):

¡Presente, porvenir, llama en que sólo quiero arder; manos frescas de la aurora, entre las hojas verdes de los chopos -imayo!-, con agua libre al pie y sin jardinero; manos, todas cuerpo desnudo, que tan bien vienen a mis manos ávidas! 
¡Todo lo vivo y por vivir en mí; yo

todo en lo vivo y por vivir; con los recuerdos nada más, de lo que no ha pasado todavía, de lo que va a venir seguramente!

Tras los dos endecasílabos iniciales, la cesura del tercer verso, alejandrino, divide el adjetivo "verdes", con el consecuente encabalgamiento léxico: "en-tre-las-hó-jas-vér $(6+1=7)$ // des-de-los-chó-pos-má-yo". El resto de la medida de los versos del poema es endecasilábica. Es interesante destacar la reiteración de ciertas palabras, típica de la técnica simbolista, así como el choque y la dislocación acentual del verso 7 ("tó-do-lo-ví-voy-por-vi-vír-en-mí-yo"), los juegos de sonoridades y rimas y aliteraciones o el predominio de sintagmas nominales.

La métrica del modernismo llegó hasta los poetas críticos con el movimiento. Enrique González Martínez emplea igualmente esta clase de alejandrino con terminación en monosílabo y de acentuación aguda en el primer hemistiquio:

Y sé fundirme en las plegarias del paisaje y en los milagros de la luz crepuscular...

Mas en mis reinos subjetivos...

se agita un alma con sus goces exclusivos, su impulso propio y su dolor particular...

Al margen de otras influencias estilísticas, léxicas o temáticas, en lo que respecta a la métrica, como se ha dicho ya, la presencia francesa, y concretamente de Verlaine, en la poesía hispánica es importante. En este sentido, Erwin K. Mapes estudió la huella de las lecturas francesas darianas en el libro titulado L'influence française dans l'oeuvre de Rubén Darío, donde destaca no sólo su conocimiento del francés y de la poesía moderna que se hacía entonces, sino del tratado de versificación de Banville. Aunque existan opiniones contrarias, como la de Osvaldo Bazil, contemporáneo de Darío, o la de Enrique Anderson Imbert ${ }^{9}$, parece indiscutible que la impronta francesa hizo

$\overline{9}$ Cfr. FERRERES, Rafael: Verlaine y..., cit., p. 63; ANDERSON IMBERT, Enrique: La originalidad de Rubén Dario. Buenos Aires: Centro Editor de Amé- 
mella en su poesía y en toda la poesía hispánica, dando lugar a una renovación necesaria. El poeta nicaragüense, en La vida de Rubén Dario escrita por él mismo, reconoció que, a partir de la lectura de los poetas franceses, se propuso revitalizar la métrica hispánica, lo que llevó a cabo fundamentalmente desde Prosas profanas en adelante, con nuevas combinaciones métricas, versos con cambios de acentuación, rimas interiores, prosa rítmica, etc. El mismo título del libro recuerda el poema titulado "Prose pour des Esseintes" de Mallarmé y remite no sólo al auge de la prosa poética en la época, sino a la poesía hímnica religiosa. El propósito de renovación formal incluía las estrofas tradicionales, como el soneto, por ejemplo. Además de haber escrito sonetos clásicos, introduce algunas variaciones. Una modificación innovadora es el empleo de versos alejandrinos, muy a menudo con rima cruzada en los cuartetos. En Rubén Darío son numerosos los sonetos alejandrinos. Se encuentran ya en $A z u l$.. y aparecen igualmente en los sucesivos poemarios. También escribe sonetos en arte menor, caso de "Mía", en hexasílabos, con rima abrazada en el primer cuarteto y cruzada en el segundo cuarteto. El sonetillo existía en la poesía anterior, pero Darío lo usa probablemente a partir de la lectura de Verlaine y Baudelaire, como indica Mapes, aunque ya Núñez de Arce, a quien admiraba, había escrito cuatro sonetillos en 1873 con el título de "Velut Umbra". Otra variación dariana es "El soneto de trece versos", de Cantos de vida y esperanza, en versos de nueve sílabas, con rima abrazada en los cuartetos, combinando masculina y femenina, y con el último verso diseminado en la página, en forma de escalera. Verlaine había escrito también un soneto de quince versos. En "Un soneto a Cervantes", de Cantos de vida y esperanza, combina versos de once y siete sílabas, aunque son los endecasílabos los mayoritarios. En el mismo libro otro soneto, "Melancolía", vuelve a presentar la combinación de endecasílabos y heptasílabos, a los que se suman los alejandrinos. En sus poemas, Darío alterna, como Verlaine, versos de sílabas pares e impares, disloca acentos, usa cesuras poco frecuentes, muchas aliteraciones y encabalgamientos ${ }^{10}$.

rica Latina, 1967 , p. 81.

10 MAPES, Erwin K.: L'influence française dans l'oeuvre de Rubén Dario. París: 
En sus escritos críticos y teóricos, en los que está siempre presente la preocupación formal, a menudo expone Rubén Darío una visión decadente y simbolista de la poesía y de la literatura, que liga a la belleza y al arte, a la música y a la idea $^{11}$. Así se aprecia, por ejemplo, en las "Palabras liminares" a Prosas profanas, y, años después, en el prefacio a Cantos de vida y esperanza, donde insiste en la "aristocracia del pensamiento" y la "nobleza del Arte", asociando el modernismo, en el que toma la responsabilidad de su inicio, con la libertad rítmica y métrica, las innovaciones versolibristas y la recuperación de formas clásicas ${ }^{12}$. En "Historia de mis libros" reconoció sus fuentes y deudas con distintos autores franceses, y en Los raros y "Los colores del estandarte" reiteró su filiación con la poética verlainiana y su teoría afín al simbolismo. En este contexto, no cabe duda de que el alejandrino francés, en sus diferentes formas, es, como sucede con otros aspectos métricos, el modelo de los alejandrinos darianos, lo que necesariamente se habrá de tener en cuenta para leer y escandir adecuadamente el alejandrino modernista aquí tratado, el cual, lejos de ser un tridecasílabo, no es, en realidad, sino un alejandrino, es decir, un verso de catorce sílabas cuyos acentos principales recaen en la sexta y duodécima sílabas.

\section{Bibliografía}

ALONSO, Dámaso: Poetas españoles contemporáneos. Tercera edición aumentada. Madrid: Gredos, 1965.

ANDERSON IMBERT, Enrique: La originalidad de Rubén Dario. Buenos Aires: Centro Editor de América Latina, 1967.

Champion, 1925, pp. 93-95 y 118-138; FERRERES, Rafael: Verlaine y..., cit., pp. 105-106.

11 Vid. UTRERA TORREMOCHA, Ma Victoria: "La crítica literaria de Rubén Darío", en Cristóbal Cuevas (ed.), Rubén Dario y el arte de la prosa. Ensayo, retratos y alegorías. Málaga: Publicaciones del Congreso de Literatura Española Contemporánea, 1998, pp. 79-102.

12 DARÍO, Rubén: "Palabras liminares" a Prosas profanas y "Prefacio" a Cantos de vida y esperanza, en El modernismo y otros ensayos. Edición de Iris M. Zavala. Madrid: Alianza, 1989, pp. 49-52. 
BRUNEL, Pierre: "Sur trois titres verlainiens: Poèmes saturniens, Fêtes galantes, Romances sans paroles", en Steve Murphy (dir.), Lectures de Verlaine. 'Poèmes saturniens', 'Fêtes galantes', 'Romances sans paroles'. Rennes: Presses Universitaires de Rennes, 2007.

DARÍO, Rubén: El modernismo y otros ensayos. Edición de Iris M. Zavala. Madrid: Alianza, 1989, pp. 49-52.

DOMÍNGUEZ CAPARRÓS, José: "Métrica y poética en Rubén Darío", en Tomás Albaladejo, Javier Blasco y Ricardo de la Fuente (eds.), El modernismo. Renovación de los lenguajes poéticos I. Valladolid: Universidad de Valladolid, 1990, pp. 36-44.

FERRERES, Rafael: Verlaine y los modernistas españoles. Madrid: Gredos, 1975. MAPES, Erwin K.: L'influence française dans l'oeuvre de Rubén Darío. París: Champion, 1925.

TORRE, Esteban: 33 poemas simbolistas, Baudelaire, Verlaine, Rimbaud, Mallarmé. Edición bilingüe y traducción de Esteban Torre. Madrid: Visor, 1995.

-El ritmo del verso (Estudios sobre el cómputo silábico y la distribución acentual, a la luz de la Métrica Comparada, en el verso español moderno). Murcia: Servicio de Publicaciones de la Universidad de Murcia, 1999. - Métrica española comparada. Sevilla: Servicio de Publicaciones de la Universidad de Sevilla, 2000.

UTRERA TORREMOCHA, Ma Victoria: "La crítica literaria de Rubén Darío", en Cristóbal Cuevas (ed.), Rubén Dario y el arte de la prosa. Ensayo, retratos y alegorías. Málaga: Publicaciones del Congreso de Literatura Española Contemporánea, 1998, pp. 79-102.

VERLAINE, Paul: Poesías. Traducción de Carlos Pujol. Madrid: Trieste, 1986.

—Oeuvres poétiques. Edición de Jacques Robichez. París: Garnier, 1995. 